\title{
¿Hasta qué punto debemos reconstruir el patrimonio destruido? Consejos en su salvaguardia y medidas de conservación preventiva
}

Yessica Espinosa | historiadora del arte y técnico de conservación y gestión del patrimonio cultural

URL de la contribución <www.iaph.es/revistaph/index.php/revistaph/article/view/4101>

A lo largo de las distintas épocas históricas ha sido mucho y muy variado el patrimonio destruido tanto por la mano del hombre como por desastres naturales. Son muchos los elementos que causan daños enormes al patrimonio cultural mundial. Sólo algunos son reversibles. Nuestro deber es conservarlo, salvaguardarlo y hacérselo llegar a las siguientes generaciones en las mejores condiciones posibles, para que lo conozcan y continúen protegiéndolo. A continuación presentamos varias de estas causas de destrucción y aportamos algunas recomendaciones extraídas del análisis de los más relevantes profesionales del sector.

Para entender por qué históricamente se arrasan sitios arqueológicos y patrimoniales como parte de estrategias terroristas, tenemos que retrotraernos al origen del concepto de patrimonio y a su propia evolución. Se trata de un producto genuino de la cultura europea, un concepto que tiene su origen en la Francia del siglo XVIII, ligado a la llustración y vinculado particularmente con la arquitectura. En aquel momento hacía alusión a las ruinas y monumentos que recordaban la historia de los pueblos, obras que, por su carácter singular, reunían una serie de valores históricos, morales y sociales que los convertían en verdaderos símbolos nacionales.

Un monumento se identifica como símbolo nacional cuando, en caso de conflicto bélico, el "enemigo" intenta atentar contra él. Recordemos el reciente atentado contra el patrimonio en Palmira, Homs o Alepo (destrucción de la gran mezquita omeya y su minarete del siglo XI, y la catedral armenia), entre otros.

También la destrucción patrimonial puede deberse a causas naturales. Cabe citar el terremoto sucedido en
2003 en la ciudadela de Bam (Irán) y el de 2006 sobre el templo de Prambanan (Indonesia). Pero no no se trata solo de los movimientos sísmicos, también el cambio climático o los incendios (como el ocurrido en 2002 en la Ciudad Vieja de Edimburgo) afectan a la conservación del patrimonio.

¿Reconstruir el patrimonio? Sí, pero estableciendo límites; sabiendo hasta qué punto intervenir o añadir nueva arquitectura en un monumento sin que éste pierda su identidad ni se convierta en algo completamente diferente. Ahora bien, atendiendo a la "buena praxis de la restauración del patrimonio", no debemos reconstruirlo devolviéndole su estado original, como si nada hubiese pasado, haciendo tabula rasa, sino más bien haciéndolo de manera que se entienda lo que ha sucedido, estableciendo adecuados planes de conservación preventiva ${ }^{1}$, y dejando patentes todas las fases históricas del bien.

Sin duda, todo lo que los desastres naturales y humanos han producido en el patrimonio mundial acentúa la necesidad de contar con unos programas específicos de prevención y medidas de emergencia ${ }^{2}$, y con profesionales cualificados para intervenir en esas circunstancias, además de mecanismos de coordinación institucional apropiados. Pues la conservación y protección patrimonial debe ser responsabilidad de todos. Y sabemos que el patrimonio cultural mundial es vulnerable en distintos ámbitos: político e institucional; económico; o técnico, relacionado con la aplicación de medidas poco eficientes en preservar el patrimonio de los pueblos.

Desde el siglo XIX muchos se oponen a reconstruir porque implicaría atentar también contra la forma original del monumento. Así, Adolphe Napoléon Didron, histo- 


\begin{abstract}
a debate Patrimonio, terrorismo y desastres naturales ¿Cómo prevenir y abordar los enormes daños al patrimonio cultural mundial?
\end{abstract}

| coordinan Francisco Javier López Morales, Francisco Vidargas

riador del arte y arqueólogo francés, opinaba que era "mejor consolidar los monumentos antiguos que repararlos, mejor repararlos que restaurarlos y mejor restaurarlos que rehacerlos." (CAMERON, 2017)

Por su parte, la Carta de Cracovia se muestra más conservadora aduciendo que "la reconstrucción de un edificio en su totalidad, destruido por un conflicto armado o por desastres naturales, es solo aceptable si existen motivos sociales o culturales excepcionales que están relacionados con la identidad de la comunidad entera" (CARTA, 2000). Esta carta también considera el turismo cultural como un riesgo, y recomienda anticipar sistemas apropiados de prevención, así como la creación de planes de actuación de emergencia.

En 2003, De Naeyer nos recomendaba que "la conservación no debe poner trabas a la arquitectura, y la buena arquitectura debe respetar y promover el recuerdo [...]. La buena arquitectura debe salvaguardar, garantizar su permanencia rescatando los materiales antiguos, las estructuras y los espacios históricos" (DE NAEYER, 2003: 164).

En nuestra opinión, en la actualidad deberíamos inclinarnos más hacia los postulados de Cesare Brandi: "La restauración debe dirigirse al restablecimiento de la unidad potencial de la obra, siempre que esto sea posible sin cometer una falsificación artística o una falsificación histórica, y sin borrar huella alguna del transcurso de la obra de arte a través del tiempo" (BRANDI, 1988).

Un ejemplo a destacar, modelo de la aplicación de este criterio, sería la ordenación de los restos de la iglesia de Salemi (Sicilia), restaurada por Álvaro Siza y Roberto Collovà en el año 2000, donde se limitaron a consolidar lo poco conservado del templo barroco tras el seísmo sobrevenido en 1968, sin soslayar la condición de ruina del monumento, pero sugiriendo, a través del tratado del suelo, sus dimensiones y formas originales. Algunos considerarán que debería haber sido restaurada y no únicamente consolidados sus restos; pero si tenemos en cuenta la Carta de Venecia ${ }^{3}$, la restauración debe ser un proceso de carácter excepcional y "debería detenerse allí donde comienzan las hipótesis" de cómo hubiera sido. Obviamente debemos olvidarnos de la "anastilosis"4 y con ello cualquier otro tipo de restauración que siga la unidad de estilo. Toda intervención "deberá llevar el sello de su época" (PALOMERO PÁRAMO, 2017: 104). Asimismo, toda restauración siempre "deberá estar precedida y acompañada de un estudio arqueológico e histórico del monumento" (CARTA, 1964: artículo 9).

Nuestra conclusión y recomendación es que resulta de vital importancia el respeto a los restos originarios y que toda intervención que se realice debe se discernible y reversible. Además de establecer planes de protección continua ante amenazas posibles del patrimonio cultural mundial.

\section{NOTAS}

1. Recientemente está empezando a distinguirse, frente a otras, una tecnología aplicada a la gestión y conservación del patrimonio: la tecnología BIM (Building Information Modeling). Aplicada al ámbito del patrimonio arquitectónico, tiene el potencial de mejorar los procesos de trabajo en su investigación, conservación y difusión, así como de obtener una mayor calidad de dichos procesos, una mejor trasmisión de los valores culturales y un ahorro en los recursos.

2. Segundo Protocolo de la Convención de La Haya de 1954 para la Protección de los Bienes Culturales en caso de Conflicto Armado. La Haya, 26 de marzo de 1999. Artículo 5, capítulo 2 <http://unesdoc.unesco.org/images/0013/001306/130696sb.pdf> [Consulta: 02/01/2017]

3. Carta de Venecia (1964), versión traducida por María José Martínez Justicia a partir del texto italiano. Véanse principalmente sus artículos 9-13 relativos a la restauración.

4. Recomposición de las partes existentes del monumento, pero desmembradas. Conocida comúnmente como restauración por estilo. 
_a debate Patrimonio, terrorismo y desastres naturales ¿Cómo prevenir y abordar los enormes daños al patrimonio cultural mundial?

| coordinan Francisco Javier López Morales, Francisco Vidargas

\section{BIBLIOGRAFÍA}

- BRANDI, C. (1988) Teoría del restauro. [1963] Madrid: Alianza, 1988

- CAMERON, C. (2017) ¿Hay que reconstruir el patrimonio cultural? Correo de la Unesco. Un solo mundo, voces múltiples [en línea]. Julio-septiembre, $2017<$ https://es.unesco.org/ courier/2017-julio-septiembre/hay-que-reconstruir-patrimoniocultural> [Consulta: 09/01/2018]

- CARTA de Cracovia (2000) Principios para la conservación y restauración del patrimonio construido [en línea] <http:// ipce.mecd.gob.es/dam/jcr:b3b6503d-cf75-4cb0-adaf226740ebd654/2000-carta-cracovia.pdf> [Consulta: 02/01/2017]

- CARTA de Venecia (1964) <http://ipce.mecd.gob.es/dam/ jcr:b55d37b1-0009-4fec-b46f-364cfdd78b9d/1964-cartavenecia.pdf> [Consulta: 09/01/18]

- DE NAEYER, A. (2003) Tendencias actuales en la restauración en Europa. En RIBERA, J. (ed.) AR\&PA. Actas del Congreso Internacional "Restaurar la memoria". Valladolid: Junta de Castilla y León, 2002, p. 164-175

- GONZALO DEL MORAL, A. (2016) Los desastres naturales destruyen patrimonio de la humanidad. Viaje a Ítaca. 26 de agosto de 2016. Blog de rtve [en línea] <http://blog.rtve.es/ viajesyturismo/2016/08/los-desastres- naturales-destruyenpatrimonio-de-la-humanidad.html> [Consulta: 07/12/2017]

- HERNÁNDEZ MARTíNEZ, A. (2007) Conservation and restoration in Built Heritage: a Western European Perspective. En GRAHAM, B.; HOWARD, P. (ed.) The Ashgate Research Companion to Heritage and Identity. London: Ashgate, 2007, pp. 371-400

- MILETO, C. (2006) La Conservación de la Arquitectura: materia y mensajes sensibles. Loggia: Arquitectura $y$ Restauración, n. ${ }^{\circ}$ 19, 2006, pp. 20-33

- NOGUERA GIMÉNEZ, J. F. (2002) La conservación del Patrimonio Arquitectónico. Debates heredados del siglo XX. Ars Longa, 2002, pp. 107-123 (Cuadernos de Arte no 11, Departament d' Historia de l'art, Universitat de Valencia)

- PAlOMERO PÁRAMO, J. (ed.) (2017) Roma Qvanta Fvit Ipsa Rvina Docet: Nicole Dacos In Memoriam. Huelva: Universidad de Huelva, Publicaciones, 2017

- PARDO FERNÁNDEZ, M. ${ }^{a}$ A. (2013) El arquitecto José Menéndez-Pidal y sus criterios de restauración monumental sobre los conjuntos históricos artísticos. Laboratorio de Arte, n. ${ }^{\circ} 25,2013$, pp. 811-827

- RODEGHIERO, B. (2008) Permanencia y transformación en arquitectura. Gibellina y Salemi: ciudades usadas. Tesis de doctorado inédita. Universidad Politécnica de Cataluña

- ROdRígueZ TEMIÑO, I. (2004) El expolio del Patrimonio.
La arqueología herida. Del ayer para el mañana. Medidas de Protección del Patrimonio. Valladolid: Fundación del Patrimonio Histórico de Castilla y León, 2004

- RODRíguez TEMiÑo, I. (en prensa) El Patrimonio Arqueológico de la A a la Z. Proteger, conservar, difundir, sensibilizar sobre la fragilidad de la historia

- RUBIO, L.; PONCE, G. (ed.) (2012) Gestión del Patrimonio Arquitectónico, cultural y medioambiental. Enfoques y casos prácticos. Alicante: Publicaciones de la Universidad de Alicante, 2012 